The New Despotism 



\title{
JOHN KEANE
}

\author{
The New \\ Despotism
}

HARVARD UNIVERSITY PRESS

Cambridge, Massachusetts

London, England

2020 
Copyright (C) 2020 by John Keane

All rights reserved

Printed in the United States of America

\section{First printing}

Cover design: Lisa Roberts

Cover art: BrilliantEye | Getty Images

9780674246690 (EPUB)

9780674246706 (MOBI)

9780674246713 (PDF)

The Library of Congress has cataloged the printed edition as follows:

Names: Keane, John, 1949- author.

Title: The new despotism / John Keane.

Description: Cambridge, Massachusetts : Harvard University Press, 2020. |

Includes bibliographical references and index.

Identifiers: LCCN 2019056411 | ISBN 9780674660069 (cloth)

Subjects: LCSH: Authoritarianism. | Democracy. | Democratic centralism.

Classification: LCC JC480.K43 2020 | DDC 320.53-dc23

LC record available at https://lccn.loc.gov/2019056411 
For George and Alice, always 
